\title{
Metodologias ativas auxiliando no aprendizado das ciências morfofuncionais numa perspectiva clínica: um relato de experiência
}

\author{
Active methodologies assisting in learning the morphological and functional sciences in \\ a clinical perspective: an experience report \\ Mússio Pirajá Mattos ${ }^{1 *}$
}

${ }^{1}$ Farmacêutico. Mestre em Ciências Farmacêuticas pela Universidade Federal da Bahia (UFBA). Professor da Universidade Federal do Oeste da Bahia (UFOB).

\begin{abstract}
Resumo
Introdução: o estudo da anatomia é encarado algumas vezes com obstáculos que não permitem motivação e engajamento dos estudantes prejudicando o seu desempenho. É importante renovar e buscar outras práticas pedagógicas, inserindo metodologias inovadoras, que permitam dinamizar as aulas das ciências morfofuncionais favorecendo a formação de profissionais críticos, reflexivos e com maior tomada de decisões. Objetivo: relatar a experiência no uso de metodologias ativas no processo de ensino e aprendizagem da disciplina Morfofuncional no curso de Medicina da UFOB. Metodologia: realizou-se um relato observacional e descritivo das metodologias ativas no processo de ensino e aprendizagem utilizados na disciplina Morfofuncional de forma interdisciplinar e inovadora. Os métodos ativos utilizados foram mapa conceitual, estudo de caso e construção de peças anatômicas, na qual os discentes foram instruídos a confeccionar modelos anatômicos didáticos que auxiliassem na compreensão da anatomia dos diferentes sistemas do corpo humano, associando a fisiologia e a aplicação clínica para dar significado ao aprendizado. Resultados: as peças anatômicas desenvolvidas estão relacionadas com: deformidade do raquitismo; distrofia muscular de duchenne; condromalácia patelar; acúmulo de cristais de ácido úrico na articulação do osso metatarsal; lesão no ligamento colateral medial do joelho; síndrome do ovário policístico; doença de crohn; endometriose; hipertireoidismo e a gastrite. Os discentes mostraram-se satisfeitos com a dinâmica anatômica, principalmente com absorção do conhecimento e a aplicação clínica. Conclusão: a experiência permitiu uma boa alternativa no ensino das ciências morfofuncionais estimulando a criatividade, o trabalho interdisciplinar, motivação ao trabalhar com problemas reais, interesse, investigação, planejamento, execução e construção do conhecimento.
\end{abstract}

Palavras-chave: Anatomia Clínica. Educação médica. Aprendizagem ativa. Ensino.

\begin{abstract}
Introduction: the study of anatomy is sometimes faced with obstacles that do not allow students' motivation and engagement to impair their performance. It is important to renew and seek other pedagogical practices, inserting innovative methodologies, that allow to stimulate the classes of the morphofunctional sciences favoring the formation of critical professionals, reflective and with greater decision making. Objective: to report the experience in the use of active methodologies in the teaching and learning process of discipline Morphofunctional in the medical course of the UFOB. Methodology: an observational and descriptive account of the active methodologies in the teaching and learning process used in the Morphofunctional discipline in an interdisciplinary and innovative way was carried out. The active methods used were conceptual map, case study and construction of anatomical pieces, in which the students were instructed to make anatomical didactic models that aided in understanding the anatomy of the different human body systems, associating physiology and clinical application to give meaning to learning. Results: the anatomical pieces developed are related to: rickets deformity; duchenne muscular dystrophy; chondromalacia patelar; the accumulation of uric acid crystals in the metatarsal bone joint; injury to the medial collateral ligament of the knee; polycystic ovarian syndrome; crohn's disease; endometriosis; hyperthyroidism and gastritis. The students were satisfied with the anatomical dynamics, mainly with absorption of knowledge and clinical application. Conclusion: the experience allowed a good alternative in the teaching of the morphofunctional sciences stimulating creativity, interdisciplinary work, motivation when working with real problems, interest, research, planning, execution and construction of knowledge.
\end{abstract}

Keywords: Clinical anatomy. Education, Medical. Active Learning. Teaching.

\section{INTRODUÇÃO}

Atualmente a anatomia humana no curso de medicina ocorre através do modelo tradicional, utilizando

Correspondente/Corresponding: *Mússio Pirajá Mattos - End: Universidade Federal do Oeste da Bahia, Centro das Ciências Biológicas e da Saúde, Rua Professor José Seabra de Lemos, 316, (Gabinete 38), Recanto dos Pássaros, CEP 47808-021, Barreiras-BA, Brasil - Tel: (71) 99157-8962 - E-mail: mussiopiraja@hotmail.com aulas expositivas seguidas de aula prática em laboratório, apresentando figuras, vídeos, modelos anatômicos, livros atlas e textos. No entanto, o estudo da anatomia é encarado algumas vezes com obstáculos que não permitem motivação e engajamento dos estudantes, prejudicando o seu desempenho (BRASIL, 2001; LEE; HAMMER, 2011; REIS et al., 2013). É importante renovar e buscar outras práticas pedagógicas, inserindo metodologias inovadoras, 
que permitam dinamizar as aulas das ciências morfofuncionais, favorecendo a formação de profissionais críticos, reflexivos e com maior tomada de decisões (CEZAR et al., 2010; TRINDADE; DAHMER; REPPOLD, 2014).

A metodologia tradicional não estimula adequadamente o desenvolvimento da autonomia, capacidade de análise, julgamento e avaliação, bem como, o raciocínio crítico, investigativo e criativo (MAMEDE et al., 2001). Esse método hipervaloriza o aspecto biológico e a fragmentação do conhecimento com consequente desvalorização dos demais determinantes do processo saúde-doença como os elementos psicológicos, sociais, históricos e ambientais (COSTA, 2005). Essa metodologia contribui para formação de especialistas, o que acaba dificultando a resolução de problemas comuns e de maior demanda nos serviços de saúde, além de comprometer a formação de um profissional que possua as competências necessárias a prática médica (PRISLIN; SAULTZ; GEYMAN, 2010).

No método tradicional, é apresentado inicialmente, a teoria e dela parte para a prática e o método ativo parte da prática e dela busca a teoria (SOUZA; IGLESIAS; PAZIN-FILHO, 2014). No método ativo o professor elabora situações que estimulam os estudantes a investigar, permitindo que eles sejam os protagonistas na construção dos saberes, ao invés de oferecê-lo pronto através das aulas expositivas. Há a necessidade de formar discentes que aprendam a pensar e correlacionar teoria e prática, buscando de modo adequado a resolução de problemas de saúde cotidianos.

A tarefa de lidar com diferentes métodos de ensino é algo complexo e exige mudanças de alguns hábitos. É comum que os docentes universitários utilizem aulas expositivas, predominantemente, e esse hábito reforça a passagem de conteúdos prontos e determinados, onde os próprios alunos já esperam do professor a contínua e passiva exposição dos assuntos que serão aprendidos. É importante a utilização de diferentes materiais de ensino que estimulem a participação ativa e o envolvimento constante do aluno para sua formação. O professor é responsável por selecionar diferentes estratégias de ensino que possibilitem a melhoria do processo laboral e integralidade do cuidado ao paciente (CYRINO; TORALLES-PEREIRA, 2004; ZANOLLI, 2004).

A ideia de realizar o presente trabalho surgiu da necessidade de estimular mudanças no processo de formação dos estudantes do curso de Medicina da Universidade Federal do Oeste da Bahia - UFOB. É importante formar profissionais com competências relacionadas com o trabalho em equipe e, consequentemente ações junto ao serviço de saúde e comunidade. Para que ocorram mudanças, são necessárias iniciativas que permitam aprender com competência, responsabilidade e sensibilidade. As metodologias ativas expõem os alunos a problemas e desafios que mobilizem o seu potencial intelectual, associando uma profunda observação crítica da realidade, tornando-o o centro do processo ensino e aprendizagem, sendo corresponsável pela construção do conhecimento (BASTOS, 2006; MITRE et al., 2008).
Este artigo descreve as atividades de ensino e extensão do projeto intitulado "Desafio anatômico: Metodologias ativas da disciplina morfofuncional capazes de auxiliar no aprendizado de anatomia humana", realizado no semestre letivo 2015.2, no município de Barreiras - BA, tendo o objetivo de relatar a experiência no uso de metodologias ativas no processo de ensino e aprendizagem da disciplina Morfofuncional do curso de Medicina da UFOB.

\section{METODOLOGIA}

No semestre letivo 2015.2, as atividades de ensino e extensão do projeto "Desafio Anatômico: Metodologias ativas da disciplina morfofuncional capazes de auxiliar no aprendizado em anatomia humana" foram apresentadas a UFOB, no Centro das Ciências Biológicas e da Saúde e aos discentes do curso de medicina. Os sistemas trabaIhados em sala foram: locomotor, digestório, endócrino e reprodutor. É válido destacar que a fisiologia foi associada com a aplicação clínica das afecções mais comuns em cada sistema.

Inicialmente os alunos da graduação e o coordenador/ docente do projeto elaboraram um planejamento onde os temas que seriam abordados deveriam ser selecionados pelos estudantes e decididas em comum acordo com o docente da disciplina, para dar significado à busca ativa no estudo da anatomia humana. Os alunos foram divididos em grupos de 5 membros, ou seja, grupos pequenos, o que possibilitava ao professor um maior contato com cada estudante, percebendo as potencialidades e fragilidades de cada um deles, podendo intervir, se necessário.

As aulas foram elaboradas com a intenção de que os alunos aprofundassem seus conhecimentos a partir da utilização de uma nota clínica no final de cada aula, para despertar no estudante uma vivência mais próxima do real, estimulando a curiosidade, motivação e aplicação dos conteúdos ministrados. A nota clínica permitia interligar os conteúdos anatômicos a situações clínicas, como por exemplo, osteogênese imperfeita, fibrodisplasia ossificante progressiva, hidrocele testicular, vasectomia, dentre outros. Nas aulas foram utilizados objetos que permitissem a associação com os movimentos articulares em execução, fazendo relação com o movimento, segmento ósseo e músculo.

Ademais, também foram utilizados casos clínicos, em diferentes momentos, relacionados ao trauma raquimedular, apendicite e diverticulite. Foram entregues aos alunos, e eles discutiram em grupos sobre qual transtorno seu caso clínico se tratava. E tinham a oportunidade de demonstrar seus conhecimentos sobre as regiões anatômicas afetadas, fisiopatologia, diagnóstico diferencial e discutir o impacto desses resultados na vida das pessoas, numa perspectiva problematizadora. Em uma das aulas foi entregue um estudo de caso aos alunos sobre o tema e eles fizeram a abertura dos casos clínicos. Nesse momento os estudantes expuseram seus questionamentos e fechavam os objetivos de aprendizagem para o estudo autodirigido. Eles foram incentivados a utilizar outras referências para complementar 
seus estudos e conhecimentos. Quando se tratava de um tema mais complexo, vídeos também foram utilizados. Além disso, foram construídos mapas conceituais para auxiliar no processo de aprendizagem.

No final da disciplina foram apresentados pelos discentes, em sala de aula, os temas selecionados, com as suas respectivas peças anatômicos: aspectos clínicos e morfofuncionais das fraturas, histerectomia, osteossarcoma, entorse, úlcera péptica, condromalácia patelar, síndrome do ovário policístico, artrite, gastrite, distrofia muscular de duchenne, doença de chron, osteoporose, endometriose, síndrome de poland, miastenia gravis e gota. Esse processo teve a finalidade de permitir a discussão desses temas e preparar os alunos para apresentar, também, para a comunidade acadêmica, contemplando os diversos cursos e funcionários, no saguão de entrada do Pavilhão 1 de aulas do campus Reitor Edgard Santos da UFOB em Barreiras-Ba.

\section{RESULTADOS}

A partir da vivência com o emprego de novas metodologias de ensino na ciência morfofuncional foi possível visualizar a contribuição no aprendizado significativo dos alunos do curso de Medicina da UFOB. Ao expor as ideias da atividade de ensino e extensão os estudantes mostraram-se, no primeiro momento, ansiosos, curiosos, surpresos e alguns relataram a dificuldade em executar essa proposta. No decorrer do semestre, com o acompanhamento da confecção das peças anatômicas e a preparação das apresentações internas (sala de aula) e externas (comunidade acadêmica), também, foi possível observar, entusiasmo, dedicação e construção de conhecimentos gerados por essa atividade.

A partir da utilização do livro atlas de anatomia e a busca ativa relacionando a fisiopatologia das doenças envolvidas e acordadas com o docente, foram confeccionados todas as estruturas dos temas propostos, usando pinturas e moldes com massas de modelar e biscuit. Foram construídas 16 peças anatômicas, das quais, 10 estão representadas nas figuras 1 e 2, onde é possível observar a deformidade nos ossos dos membros inferiores, característica do raquitismo, onde os joelhos se afastam e os tornozelos se aproximam (Figura 1-A); a atrofia do músculo bíceps braquial, característico da distrofia muscular de duchenne (Figura 1-B); a degeneração da articulação da patela na condromalácia patelar (Figura 1-C); o acúmulo de cristais de ácido úrico na articulação do osso metatarsal (Figura 1-D) e a lesão no ligamento colateral medial do joelho (Figura 1-E).

É possível, ainda, observar a peça referente à Síndrome do ovário policístico (Figura 2-A); as ulcerações no cólon ascendente e a estenose no cólon transverso na doença de Crohn (Figura 2-B); as células endometriais migrando para os ovários e provocando inflamações características da endometriose (Figura 2-C); o hipertireoidismo aumentando o volume da tireóide (Figura 2-D); e a gastrite permitindo a inflamação da mucosa gástrica na região do corpo estomacal (Figura 2-E). Essas peças anatômicas foram utilizadas como material educativo que contribuíram para as apresentações em sala de aula e para a comunidade acadêmica.

Figura 1 - Modelos anatômicos didáticos: $A$, Raquitismo; $B$, Distrofia muscular de duchenne; $C$, Condromalácia patelar; $D$, Gota e E, Entorse

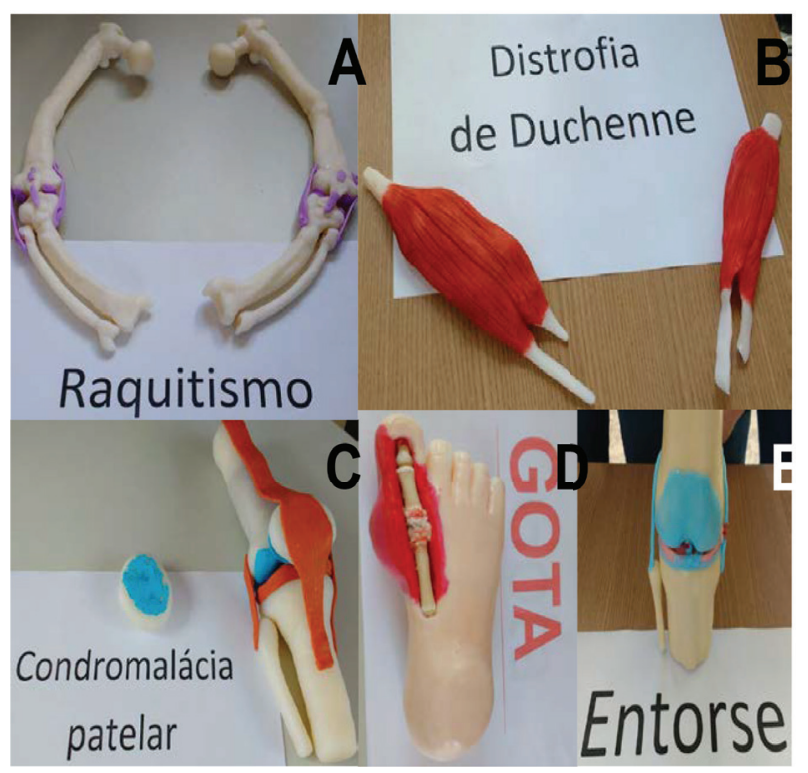

Fonte: Autor

Figura 2 - Modelos anatômicos didáticos: $A$, Síndrome do ovário policístico; B, Doença de Crohn; C, Endometriose; D, Hipertireoidismo e E, Gastrite

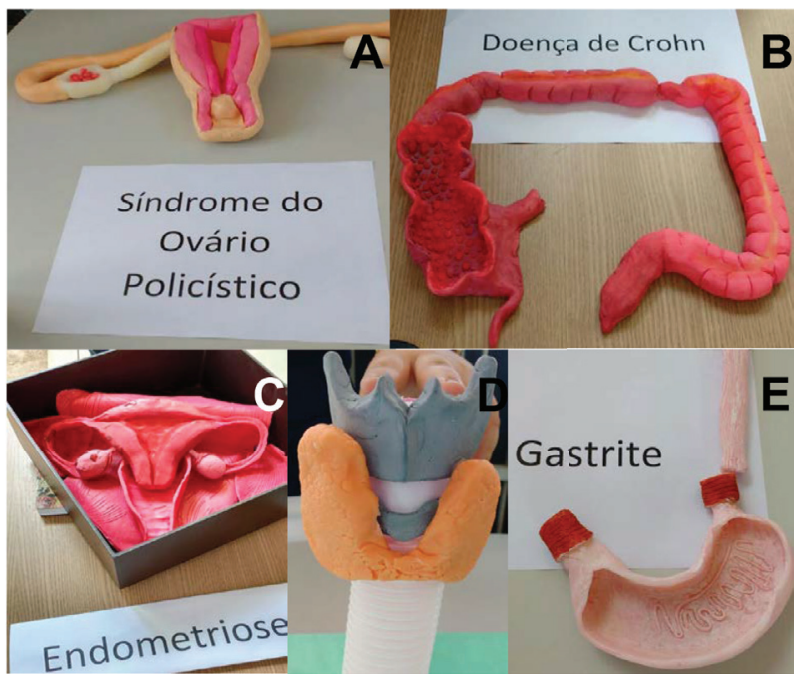

Fonte: Autor

\section{DISCUSSÃO}

O curso de medicina da UFOB foi implantado em 2014, tendo na metodologia tradicional o caminho para o processo de aprendizagem. $\mathrm{O}$ emprego de metodologias ativas no processo de ensino permitiu observar o desenvolvimento dos alunos no contexto diário, tendo como resultado a 
formação crítica e reflexiva. Dessa maneira, a utilização de recursos didáticos ativos num currículo tradicional, possibilitou uma aprendizagem diferenciada, gerando a construção do conhecimento a partir do protagonismo dos estudantes.

A metodologia utilizada foi aplicada para despertar nos alunos do curso de medicina a inserção de novos instrumentos de ensino no campo das ciências morfofuncionais. $O$ processo ensino e aprendizagem dentro da morfologia são extremamente difíceis, uma vez que a memorização das diversas estruturas e com nomes complexos, geralmente, não é um ambiente motivador.

Nas metodologias ativas há uma inversão no papel do docente e do aluno. Os discentes assumem o controle na construção do conhecimento e o docente facilita a aprendizagem (ANASTASIOU; ALVES, 2007; MITRE et al 2008). Na metodologia tradicional, a memorização como principal objetivo a ser explorado é insuficiente para alcançar a aprendizagem significativa (ANASTASIOU; ALVES, 2007). O trabalho docente não deve estar restrito, somente, a transmissão do conteúdo, mas, deve envolver os alunos da construção do conhecimento. Dessa forma, surge a necessidade do docente em propor ações que organize, desperte, construa e que vença os obstáculos dos estudantes frente a novas estratégias de ensino, o que muitas vezes é uma tarefa extremamente complexa.

Nesse contexto, utilizar métodos ativos que não faziam parte da metodologia tradicional foi um grande desafio. No primeiro momento foi bastante difícil convencer os alunos da importância dessas atividades, acarretando em mudanças frequentes na programação da disciplina. No decorrer do semestre, houve diversos questionamentos quanto à contribuição desses instrumentos para a construção significativa do conhecimento o que gerou alguns conflitos. Os alunos estavam habituados a aprendizagem por meio de aulas expositivas e ressaltavam frequentemente, a necessidade de memorizar, somente, as estruturas anatômicas presentes no livro atlas.

Diante dessa realidade, houve a necessidade de motivação e uma constante tentativa de convencimento aos alunos quanto à importância desses métodos para a construção e aplicação do conhecimento, possibilitando uma formação profissional crítica, reflexiva e com maior tomada de decisões. No processo de apropriação das novas metodologias foi possível observar importantes mudanças que foram desde incertezas, descrenças e imprevisibilidade que foram transformadas em maior adesão e aceitação no decorrer do semestre. $O$ processo de ensino e aprendizagem para além do conteúdo foi um desafio que só pôde ser conquistado pela aceitação, autonomia, proatividade e dedicação dos alunos.

A aplicação dessas metodologias de ensino permitiu observar avanços nos conhecimentos obtidos pelos graduandos, por meio das apresentações orais, habilidade de comunicação, articulação de idéias e esclarecimento de questionamento no momento da exposição para a comunidade acadêmica, além da participação em sala de aula e das notas obtidas nas avaliações teóricas, práticas e por produção. A metodologia tradicional é um método clássico que faz o aluno ser passivo em relação ao conhecimento, impedindo o aprendizado em vivências diárias (FREIRE, 1997).

De acordo com Araújo Junior et al. (2014) a construção de um modelo anatômico permite aos estudantes tornarem-se mais ativos e motivados, como também um indivíduo questionador e que não se acomoda com o que Ihe é passado. Dessa forma, as metodologias utilizadas tornaram a busca pelo conhecimento atrativo e no decorrer do tempo os alunos sentiram-se cada vez mais, aptos a interagir, construir o conhecimento e as peças anatômicas.

Os mapas conceituais feitos em sala de aula expressaram informações e conceitos já aprendidos de forma significativa. Com isso, trabalhou-se o pensamento crítico e reflexivo permitindo a autonomia na formação profissional. A associação dessas metodologias em consonância com a construção das peças anatômicas permitiu um ambiente transformador com a construção da habilidade dos alunos em relação à memorização, interação com os colegas e aproximação da realidade. Se tratando da primeira atividade, dentro desse contexto, na vida acadêmica deles, podemos dizer que essa atividade foi extremamente satisfatória por motivar e aproximar os conteúdos teóricos e práticos obtidos em sala de aula numa perspectiva clínica.

Uma característica importante foi à organização e a qualidade do material exposto, que permitiu uma articulação entre os aspectos morfofuncionais e associação com a clínica, que tornou a busca mais prazerosa pelos graduandos, principalmente quando as peças eram comparadas numa situação normal e patológica. Outro destaque foi a arguição dos visitantes na exposição do projeto a comunidade acadêmica que contribuiu para o desenvolvimento do aluno de forma individualizada e coletiva, característica importante no contexto da graduação médica.

Essa atividade permitiu que os alunos explorassem formas de orientar as pessoas que circulavam no local da amostra das peças anatômicas. Esse fato evidenciou que a criação dos modelos anatômicos foi assertiva e estimulou a criatividade, trabalho interdisciplinar, motivação ao trabalhar com problemas reais, interesse, investigação, planejamento, execução e aprendizagem significativa. Existem duas condições para a construção da aprendizagem significativa: a existência de um conteúdo potencialmente significativo e a adoção de uma atitude favorável para a aprendizagem, ou seja, a postura própria do discente que permite estabelecer associações entre os elementos novos e aqueles já presentes na sua estrutura cognitiva (MITRE et al; 2008).

Dentro desta perspectiva da re-significação da aprendizagem, o estudante precisa assumir um papel cada vez mais ativo descondicionando-se da atitude de mero receptor de conteúdos, buscando efetivamente conhecimentos relevantes aos problemas e aos objetivos da aprendizagem. Iniciativa criadora, curiosidade científica, espírito crítico-reflexivo, capacidade para auto-avaliação, cooperação 
para o trabalho em equipe, senso de responsabilidade, ética e sensibilidade na assistência são características fundamentais a serem desenvolvidas por um discente de uma metodologia ativa (KOMATZU; ZANOLLI; LIMA, 1998; SANTOS, 2005). Este fato foi nitidamente observado nos alunos, que apesar de habituados a rotina de uma metodologia tradicional, abraçaram a proposta e ultrapassaram as barreiras da aprendizagem, mostrando várias competências no decorrer do desenvolvimento da Dinâmica Anatômica.

Portanto, a experiência com a utilização de recursos didáticos ativos, Desafio Anatômico, Mapa conceitual e Estudo de caso na disciplina Morfofuncional foi importante no processo de construção do conhecimento, pois possibilitou a criação de uma memória mais eficiente com aplicação clínica e notada pelos próprios discentes, estimulando a criatividade (FREITAS et al., 2008). Ademais, o trabalho em equipe trouxe vários benefícios como liderança, planejamento, motivação e comprometimento para alcançar o objetivo determinado, características que são imprescindíveis na rotina da prática médica.

\section{CONCLUSÃO}

As metodologias ativas são novas formas de trabalhar no ensino superior que buscam romper o modelo tradicional reorganizando as aulas teóricas e práticas das disciplinas morfofuncionais promovendo maior aceitação no ensino da anatomia humana. Os discentes mostraram-se satisfeitos com a dinâmica anatômica, principalmente com absorção do conhecimento e a aplicação clínica. Desta maneira, a experiência permitiu uma boa alternativa no ensino das ciências morfofuncionais estimulando a criatividade, o trabalho interdisciplinar, motivação ao trabalhar com problemas reais, interesse, investigação, planejamento, execução e construção do conhecimento.

\section{AGRADECIMENTOS}

O autor expressa aqui o agradecimento ao Centro das Ciências Biológicas e da Saúde e aos alunos do curso de Medicina da Universidade Federal do Oeste da Bahia, Barreiras - BA, pela confecção dos modelos anatômicos neste trabalho.

\section{REFERÊNCIAS}

ANASTASIOU, L. G. C.; ALVES, L. P. Estratégias de ensinagem. In: ANASTASIOU, L.G. C. Processos de ensinagem na universidade: pressupostos para as estratégias de trabalho em aula. Santa Catarina: Ed. Joinville, 2007.

ARAÚJO JUNIOR, J. P et al. Desafio anatômico: uma metodologia capaz de auxiliar no aprendizado de anatomia humana. Medicina, Ribeirão Preto, v. 47, n. 1, p. 8-62, 2014

BASTOS, C. C. Metodologias ativas. 2006. Disponível em: <http://educacaoemedicina.blogspot.com.br/2006/02/metodologias-ativas.html>. Acesso em: 16 fev. 2017.
BRASIL. Conselho Nacional de Educação. Câmara de Educação Superior. Diretrizes Curriculares Nacionais do Cursode Graduação em Medicina. Resolução CNE/CES №. 4. Institui diretrizes curricularesnacionais do curso de graduação em medicina. Diário Oficial [da] União. Brasília. Seção 1, p. 1-6, 2001.

CEZAR, P. H. N. et al. Transição Paradigmática na Educação Médica: Um Olhar Construtivista Dirigido à Aprendizagem Baseada em Problemas. Rev. bras. educ. méd., Rio de Janeiro, v. 34, n. 2, p. 298-303, 2010.

COSTA, N. M. S. C. A formação e as práticas educativas de professores de Medicina: uma abordagem etnográfica. 2005. $201 \mathrm{f}$. Tese (Doutorado) - PUC de São Paulo, São Paulo, 2005.

CYRINO, E. G; TORALLES-PEREIRA, M. L. Trabalhando com estratégias de ensino-aprendizado por descoberta na áreada saúde: a problematização e a aprendizagem baseada em problemas. Cad. Saúde Pública, Rio de Janeiro, v. 20, n. 3, p.780-788, 2004.

FREIRE, P. Educação "bancária" e educação libertadora. In: PATTO, M. H. S. (Org). Introdução à psicologia escolar. São Paulo: Casa do psicólogo, 1977. p. 61-77.

FREITAS, L. A. M. et al. Construção de modelos embriológicos com material reciclável para uso didático. Biosci. J., Uberlândia, v. 24, n. 1, p. 91-97, 2008.

KOMATZU, R. S.; ZANOLLI, M.; LIMA, V. V. Aprendizagem baseada em problemas. In: MARCONDES, E.; GONÇALVES, E. (Org). Educação médica. São Paulo: Sarvier, 1998. p. 223-237.

LEE, J. J.; HAMMER, J. Gamification in education: What, how, why bother? Academic Exchange Quarterly, Califórnia, v. 15, n. 2, p. 146, 2011.

MAMEDE, S. et al. Aprendizagem baseada em problemas: anatomia de uma nova abordagem educacional. Fortaleza: Escola de Saúde Pública/ São Paulo: Editora Hucitec, 2001

MITRE, S. M. et al. Metodologias ativas de ensino-aprendizagem na formação profissional em saúde: debates atuais. Ciênc. Saúde Coletiva, Rio de Janeiro, v. 13, n. 2, p. 2133-2144, 2008.

PRISLIN, M. D.; SAULTZ, J. W.; GEYMAN, J. P. The Generalist disciplines in american medicine one hundred years following the flexner report: a case study of unintended consequences and some proposals for post-flexnerian reform. Acad. Med., Philadelphia, v. 85, p. 228-235, 2010.

REIS, C. et al. Avaliação da percepção de discentes do curso médico acerca do estudo anatômico. Rev. Bras. Educ. méd., Rio de Janeiro, v. 37, n. 3, p. 350-358, 2013.

SANTOS, S. S. A integração do ciclo básico com o profissional no curso de graduação em medicina: uma resistência exemplar. Rio de Janeiro: Papel \& Virtual; Teresópolis: FESO, 2005.

SOUZA, C. S.; IGLESIAS, A. G.; PAZIN-FILHO, A. Estratégias inovadoras para métodos de ensino tradicionais - aspectos gerais. Medicina, Ribeirão Preto, v. 47. n. 3, p. 284-92, 2014.

TRINDADE, C. S.; DAHMER, A.; REPPOLD, C. T. Objetos de Aprendizagem: uma revisão integrativa na área da saúde. J. Health Inform., São Paulo, v. 6, n. 1, p. 20-29, 2014.

ZANOLLI, M. Metodologias ativas de ensino-aprendizagem na área clínica. In: MARINS, J. J. N. et al. Educação médica em transformação: instrumentos para a construção de novas realidades. Rio de Janeiro: Abem; São Paulo: Hucitec, 2004.

Submetido em: $15 / 11 / 2016$

Aceito em: 15/04/2017 